\title{
Fear of childbirth and sense of coherence with their determinants in endangered and healthy pregnancies
}

\author{
Paula Emilia Złakowska ${ }^{1, A} \oplus$ \\ ${ }^{1}$ Institute of Psychology, Maria Curie-Skłodowska University, Lublin, Poland \\ A - Research concept and design, B - Collection and/or assembly of data, C - Data analysis and interpretation, \\ $D$ - Writing the article, E-Critical revision of the article, F- Final approval of article
} Złakowska PE. Fear of childbirth and sense of coherence with their determinants in endangered and healthy pregnancies. J Pre Clin Clin Res.
2020; 14(3): 90-93. doi: $10.26444 /$ jpccr/126596

\begin{abstract}
Introduction. The growing number of Cesarean sections and the percentage of women dissatisfied with perinatal care are the one of the main problems of modern gynaecology in Poland. It seems that if women with a high fear of delivery and a low sense of coherence are scanned early enough, it can contribute to better psychological care and greater satisfaction while giving birth.

Objective. The aim of the study is to compare the level of fear of childbirth and sense of coherence between endangered and healthy pregnancies.

Materials and Method. The study was conducted in one centre in Lublin, Poland, which involved 29 women in endangered pregnancies. The comparative group consists of 30 women in healthy pregnancy, tested online. Antonovsky's Sense of Coherence Scale (SOC) and Fear of Childbirth Questionnaire were used for the study.

Results. The results showed that women in endangered pregnancy significantly differ in terms of the level of fear of delivery, comprehensibility, manageability and general sense of coherence from women who are not in endangered pregnancy. The Cohen's d size indicates that women who are in high-risk pregnancy have a significantly higher level of fear of childbirth than women in healthy pregnancy. Cohen's d index also indicates that women in endangered pregnancy have a significantly lower level of comprehensibility, manageability and general sense of coherence compared to the control group.

Conclusions. Screening pregnant women with ready-made questionnaires and providing professional psychological care can possibly prevent excessive escalation of childbirth anxiety and decrease the number of Cesarean sections. By increasing the sense of coherence, we can help in better management of pregnancy and improve the overall experience.
\end{abstract}

\section{Key words}

Fear of childbirth, sense of coherence, endangered pregnancy, healthy pregnancy

\section{INTRODUCTION}

In today's medicine, the patient is treated holistically, bearing in mind not only his or her somatic state but also mental health. The phenomenon of fear of labour is unfortunately quite common among future mothers and it is a significant obstetric problem, which is more often observed in primiparas [1]. The increased fear of delivery is called tokophobia, a term introduced into the medical literature in 2000. It may manifest as nightmares, problems with concentration at work, panic attacks and somatic symptoms, which significantly impedes the life of a pregnant woman and makes them ask for a Caesarean section. The fear of childbirth itself is mainly associated with the fear of pain and previous labour complications.

Studies have shown that the cause of anxiety cannot be unambiguously determined and varies depending on the women. This phenomenon not only has a negative impact on mothers' well-being, who are more likely to fall into depression, neuroses or even postpartum psychoses, but also indicate neurological and behavioural abnormalities in the newborns of women who experienced severe stressors

Address for correspondence: Paula Emilia Złakowska, Institute of Psychology, Maria Curie-Skłodowska University, Prezydenta Gabriela Narutowicza 12, 20-400 Lublin, Poland

E-mail: p.zlakowska@gmail.com

Received: 17.07.2020; accepted: 20.08.2020; first published: 03.09.2020 during pregnancy $[2,3]$. It can be caused, among others, by placental dysfunction that regulates the flow of cortisol from the mother [4]. Cortisol affects not only the acceleration of foetal heart rate, but also increases the frequency of its movements, which may indicate a quick response of the child to maternal stress $[5,6]$. On the other hand, it has been shown that low or moderate stress may have a positive effect on the brain development and cognitive processes of the newborn [7].

In women with severe antenatal anxiety a significantly higher percentage of giving birth was observed through Caesarean section and other surgical interventions [8]. According to the EURO-PERISTAT Report, the number of births through Caesarean section in Poland is increasing, and since 2000 , this increase has risen from $19.6 \%$ to $42.2 \%$ in 2014, and is higher than the European average of $27 \%$.

A high sense of coherence seems to be a protective factor and allows women to approach pregnancy, birth and motherhood relatively calmly [9] which translates as the life orientation of a human being. The sense of coherence is a theoretical construct introduced by Aaron Antonovsky and consists of comprehensibility, manageability and meaningfulness. The most important factor seems to be the latter, i.e. the feeling that life has sense, a willingness to take on challenges and effective problem solving. When the meaningfulness is high, other factors also show an upward trend [10]. People with high sense of coherence view the world as friendly, thought- 
provoking and understandable; they are able to use their own resources to fight stress and stay in a good mental state for a long time [11].

Considering possible complications, not only somatic, but also psychological, it seems to be important to screen pregnant women with ready-made questionnaires and prove professional psychological care. This can also possibly prevent an excessive escalation of childbirth anxiety and a decrease in the number of Cesarean sections. The aim of this study is to measure the level of antenatal anxiety and the sense of coherence in pregnant Polish women.

\section{MATERIALS AND METHOD}

The study was conducted on a group of 29 women in endangered pregnancy (high-risk pregnancy) and 30 women in healthy pregnancy (low-risk pregnancy) in Lublin in 2020. From one hospital in Lublin (Samodzielny Publiczny Szpital Kliniczny $\mathrm{Nr} 4$ ), 30 women in endangered pregnancy were selected and oral consent obtained to conduct the survey. The criteria for endangered pregnancy were: maternal diabetes, autoimmune diseases, kidney diseases, wrong placenta placement, pre-eclampsia, eclampsia, IUGR, abnormalities in foetal development, oligohydramnios and polyhydramnios. Gestational was irrelevant. Criteria for inclusion in the research group were: age from $20-45$ years, single pregnancy and no history of mental diseases. Women in healthy pregnancies were tested online via surveys, the same criteria for inclusion were used.

The study tools were: Demographic and Perinatal profile, Antonovsky's Sense of Coherence Scale (SOC) and Fear of Childbirth Questionnaire [12]. The Demographic and Perinatal Profile contained: age, marriage status, area of living, number of deliveries, and gestational age. SOC Scale consists of 29 questions based on a 7-point Likert scale with scores between 29-203 points. The Fear of Childbirth Questionnaire had 9 questions with scores raging from 0-27. Data were analysed by using SPSS software.

\section{RESULTS}

29 women in endangered pregnancy and 30 women in healthy pregnancy took part in this study. The age of women in both groups was similar (women in endangered pregnancy - from $20-43$ years; $M=28.17$; $S D=5.3$; women in healthy pregnancy - from 23-45 years; $M=32.00 ; S D=5.93$ ).

The studied groups were also similar in terms of the week of pregnancy (women in endangered pregnancy - from 10-41 weeks; $M=27.41 ; S D=9.56$; women in healthy pregnancyfrom $8-38$ weeks; $M=24.60 ; S D=10.03$ ). $55.2 \%$ of women in high-risk pregnancy had never given birth, neither had $40 \%$ of women at low-risk of pregnancy. In turn, the number of deliveries among women in high-risk of pregnancy who have already given birth was one delivery $-27.5 \%$, two deliveries - $17.2 \%$, whereas among women who were in low-risk pregnancy, one delivery $-30 \%$, two deliveries $-10 \%$, and three deliveries $-20 \%$.

The place of residence did not differentiate the studied groups. $75.9 \%$ of women in endangered pregnancy and $73.3 \%$ of women in healthy pregnancy lived in the city. The remaining percentage of women in each group lived in the countryside.
In the group of women in high-risk pregnancy, $79.3 \%$ were married and $20.7 \%$ were unmarried. In the group of women who were not in high-risk, $60 \%$ were married and $40 \%$ were unmarried.

Table 1 presents descriptive statistics of fear of childbirth and scales measuring the sense of coherence, broken down into groups of women in high-risk pregnancy and lowrisk pregnancy. The normality of the distribution was also calculated using the Shapiro - Wilk $(S-W)$ test.

Table 1. Descriptive statistics of variables divided into groups

\begin{tabular}{|c|c|c|c|c|c|c|c|c|c|c|}
\hline & \multicolumn{2}{|c|}{$M$} & \multicolumn{2}{|c|}{$S D$} & \multicolumn{2}{|c|}{ MIN } & \multicolumn{2}{|c|}{ MAX } & \multicolumn{2}{|c|}{$S-W$} \\
\hline & $P_{e}$ & $P_{h}$ & $P_{e}$ & $P_{h}$ & $P_{e}$ & $P_{h}$ & $P_{e}$ & $P_{h}$ & $P_{e}$ & $P_{h}$ \\
\hline & 14.66 & 12.17 & 3.89 & 2.54 & 9.00 & 8.00 & 24.00 & 17.00 & 0.96 & 0.94 \\
\hline C & 37.62 & 44.03 & 6.72 & 9.1 & 25.00 & 28.00 & 50.00 & 65.00 & 0.97 & 0.98 \\
\hline & 40.69 & 46.00 & 7.03 & 7.66 & 27.00 & 31.00 & 53.00 & 61.00 & 0.96 & 0.97 \\
\hline & 39.21 & 39.70 & 6.90 & 7.1 & 25.00 & 25.00 & 53.00 & 53.00 & 0.96 & 0.98 \\
\hline & 117.52 & 129.73 & 17.22 & 18.94 & 86.00 & 86.00 & 150.00 & 164.00 & 0.98 & 0.97 \\
\hline
\end{tabular}

$P$-endangered pregnancy; $P$ - healthy pregnancy; $F$ - fear of childbirth: $C$ - comprehensibility; $S_{m}-$ manageability; $S_{f}$ - meaningfulness; $G_{c}-$ general sense of coherence.

Women in endangered pregnancy obtained lower mean than women in healthy pregnancy in terms of comprehensibility, sense of meaningfulness, sense of manageability and general sense of coherence and higher mean in the intensity of fear of childbirth. The statistical significance of these differences was analysed by the Student's $t$ test for independent samples (Tab. 2). The level of fear of childbirth in the group of women in high-risk pregnancy according to norms is slightly increased, while in the group of women in low-risk pregnancy, the level of fear of childbirth was low. In addition, in the group of women in high-risk pregnancy, the variable intensity of fear of delivery had a higher standard deviation (and also a higher maximum score) than in the group of women who were in healthy pregnancy. The standard deviation in the field of variables measuring the sense of coherence was higher in the group of women who were in healthy pregnancy (their maximum results are also higher - with the exception of the variable - sense of meaningfulness). In turn, the minimum values of variables were similar in both groups. Analysis by the Shapiro-Wilk test showed that the distribution of all variables in Table 1 in both groups was close to normal.

Level of fear of delivery and a sense of coherence differences between women in endangered and healthy pregnancies. The differences in the level of fear of delivery and the sense of coherence between women in endangered and healthy pregnancies were tested by the Student's t test for independent samples.

Women in endangered pregnancy significantly differed in terms of the level of fear of delivery, comprehensibility, manageability and general sense of coherence from women who were not in endangered pregnancy. There were no significant differences between the groups in terms of sense of meaningfulness. Women who were in high-risk pregnancy had a significantly higher level of fear of childbirth than women who were not. The Cohen's d size indicates that this is a big difference. In addition, women in endangered pregnancy have a significantly lower level of comprehensibility, manageability and general sense of coherence than women 
Table 2. Differences in the level of anxiety and sense of coherence in the examined groups of women in endangered and healthy pregnancies

\begin{tabular}{|c|c|c|c|c|c|c|c|}
\hline & \multicolumn{2}{|c|}{$M$} & \multicolumn{2}{|c|}{$S D$} & \multirow[t]{2}{*}{$t$} & \multirow[t]{2}{*}{$p$} & \multirow[t]{2}{*}{ d-Cohena } \\
\hline & $\mathrm{P}_{\mathrm{e}}$ & $P_{h}$ & $\mathrm{P}_{\mathrm{e}}$ & $P_{h}$ & & & \\
\hline $\mathrm{F}$ & 14.66 & 12.17 & 3.89 & 2.54 & 2.92 & 0.005 & 0.76 \\
\hline$C$ & 37.62 & 44.03 & 6.72 & 9.19 & -3.05 & 0.003 & 0.80 \\
\hline $\mathrm{S}_{\mathrm{m}}$ & 40.69 & 46.00 & 7.03 & 7.66 & -2.77 & 0.008 & 0.72 \\
\hline$S_{f}$ & 39.21 & 39.70 & 6.90 & 7.13 & -0.27 & 0.788 & - \\
\hline Gc & 117.52 & 129.73 & 17.22 & 18.94 & -2.59 & 0.012 & 0.67 \\
\hline
\end{tabular}

$\mathrm{P}_{\mathrm{e}}$ - endangered pregnancy; $\mathrm{P}_{\mathrm{h}}$ - healthy pregnancy; $\mathrm{F}$ - fear of childbirth; $\mathrm{C}$ - comprehensibility $S_{m}^{e}$ - manageability; $S_{f}$ - meaningfulness. $G_{c}$ - general sense of coherence.

who were in healthy pregnancy. Similarly, Cohen's d index also indicated big differences.

Relationship between sense of fear of delivery and sense of coherence. The relationship between the level of fear of childbirth and the sense of coherence and its components were checked separately in groups of women in high risk pregnancy and low-risk pregnancy. Pearson correlation coefficient was used.

Table 3. Relationship between sense of fear of delivery and sense of coherence in the groups of studied women

\begin{tabular}{|c|c|c|c|c|}
\hline & \multicolumn{2}{|c|}{ Women in endangered pregnancy } & \multicolumn{2}{|c|}{ Women in healthy pregnancy } \\
\hline & \multicolumn{2}{|c|}{ Fear of childbirth } & \multicolumn{2}{|c|}{ Fear of childbirth } \\
\hline & $r$ & $\mathrm{P}$ & r & $\mathrm{P}$ \\
\hline $\mathrm{C}$ & -0.28 & 0.074 & 0.21 & 0.130 \\
\hline$\underline{\mathrm{sm}}$ & -0.27 & 0.081 & -0.18 & 0.173 \\
\hline $\mathrm{S}_{\mathrm{f}}$ & 0.04 & 0.419 & 0.07 & 0.365 \\
\hline Gc & -0.20 & 0.149 & 0.06 & 0.386 \\
\hline
\end{tabular}

$C$-comprehensibility. $S_{m}$ - manageability; $S_{f}-$ meaningfulness. $G_{c}-$ general sense of coherence

No significant relationships between variables were found in any of the groups of women studied. However, in the group of women in endangered pregnancy, fear of childbirth was associated at the level of statistical tendency with comprehensibility and manageability. This relationship means that the higher the fear of delivery in high-risk pregnancy, the lower the comprehensibility and manageability. It should be noted that these are only statistical trends.

Fear of delivery and age and week of pregnancy. There was no significant relationship between the fear of childbirth and age in the group of women in endangered pregnancy $(r=0.01$; $p=0.494)$, nor in the group of women in healthy pregnancy $(r=-0.12 ; p=0.266)$. Similarly, there was no statistically significant correlation between the fear of delivery and the week of pregnancy in the group of women in high-risk pregnancy $\left(r_{s}=-0.14 ; p=0.236\right)$, nor in the group of women in low-risk pregnancy $\left(r_{s}=-0.19 ; p=0.162\right)$.

Intensity of fear of childbirth - differences due to place of residence, previous births and marital status. There was no significant differences in the fear of childbirth $(Z=-1.22$; $p=0.221)$ between women living in the city $(M=13.68$; $S D=3.46)$ and living in the countryside $(M=12.53$; $S D=3.54)$. Similarly, multiple deliveries did not differentiate the level of fear of delivery. Women who had previously given birth $(M=12.84 ; S D=3.51)$ had a lower mean of anxiety before delivery than women who were given birth for the first time $(M=14.00 ; S D=3.41)$; however, this was not a statistically significant difference $(Z=-1.59 ; p=0.113)$. Marital status was also not a factor that affected differences in the level of fear of childbirth. Maidens $(M=13.72 ; S D=2.74)$ did not differ from married women $(M=13.24 ; S D=3.79)$ in terms of fear of delivery $(Z=-0.96 ; p=0.338)$.

\section{DISCUSSION}

It seems that the screening of pregnant women in terms of their mental state should be an indispensable part of prenatal visits. Many studies indicate the positive impact of psychological care on the experience of childbirth and the large need of women in terms of support in that time.

In this study, the differences between women in endangered pregnancy and healthy pregnancy were large, as Cohen's d indicated, both in terms of fear of childbirth and in the sense of coherence. However, the relationship between the sense of coherence and fear of giving birth in the group of women in high-risk pregnancy was only at the level of statistical tendency - which means that this relationship is either absent or very weak. This is probably because of the fact. that the lower sense of coherence in the group of women in endangered pregnancy is not only associated with fear of childbirth, but also with other factors not taken into account in this study, e.g. fear of the child's life, difficulties associated with daily functioning in this condition. etc. [13]. A similar study by Mohamamdirizi et al. [14] also found large statistical differences between women in high-risk pregnancy and low-risk pregnancy, and no significant differences in the fear of delivery. Nor did they detect a statistically significant correlation between the sense of coherence and fear of delivery, or any other statistical differences in terms of mother's age, partner's age, gestational age, and BMI between the studied groups of women. A large Japanese study by Takegata, and Haruna et al. [15] showed statistically significant correlations between fear of delivery and a sense of coherence in healthy pregnancies. In the examined women, they found that the higher the sense of coherence the woman had, the smaller the fear of delivery. This is probably due to the general understanding of a high sense of coherence as a protective factor for our mental health. People with a high sense of coherence better explain to themselves difficult situations and solve everyday problems more easily [16]. A study by Carlsson et al. on self-efficacy in women during childbirth showed that it was positively correlated with a high sense of coherence and family support, and negatively correlated with a history of mental illness, bad attitudes, and a high sense of anxiety. Women with a high sense of effectiveness were given less epidural anesthesias during labour [17].

Ryding et al. studied the husbands/partners of pregnant women who scored high in fear on the childbirth questionnaire. Spouses had a much lower level of anxiety and depressive symptoms than pregnant women; none of them achieved very high results regarding fear of delivery, and therapy or extensive education did not change their anxiety levels. Partners' bad experience was only associated with an unforeseen and sudden Cesarean section [18]. 
A metasynthesis by Sheen and Slade focused on isolating the factors that cause fear of giving birth; the common variable for most pregnant women was fear of the unknown experience of childbirth and its unpredictability. The most important factors causing fear, according to this analysis, were: lack of information about delivery and procedures from medical professionals, fear of pain, low belief in own abilities, and minimal sense of control and possibility of potential injury [19]. Alder et al. linked fear of delivery and pronounced the antenatal cortisol awakening response with a negative childbirth experience [20]. According to Goutaudier et al., many women also suffer from post-partum PTSD. They suggested that childbirth is a very traumatic and threatening experience, which can lead to many psychological disorders and should be proceed with caution [21].

In order to prevent and treat tokophobia, cognitive therapy and psycho-education with relaxation have been found to be useful $[22,23]$. Not only women with a high Fear of Childbirth Questionnaire score, but every pregnant woman should have access and the opportunity to have psychological consultation, followed by extensive information on pregnancy and childbirth [24]. Hosseini et al. found that education had twice as much effect on reducing fear of delivery than hypnosis [25]. A study by Sekizuka. Nakamura et al. concluded that a low SOC score is correlated with a low depression score in pregnant women. Moreover, women in the postpartum period scored higher in the depression questionnaire than in prepartum [9], which give us one more reason to actively search for women with psychological problems while pregnant.

\section{CONCLUSION}

This study, as well as many others on similar subjects, was aimed at drawing the attention of medics to the growing problem of women's psychological problems during pregnancy. Many doctors focus on successfully bringing pregnancy to termination, but sometimes forget about providing women with psychological care. Particularly noteworthy in this study is the significantly higher level of fear of childbirth in women in endangered pregnancy, which suggests that it would be beneficial for Departments of Obstetrics and Pathology of Pregnancy to assess women whom they admit by a psychologist. This could help in psychological care of patients and potentially reduce the number of Caesarean sections [19]. Factors such as gestational age, marital status, number of previous births and place of residence do not seem to have a significant impact on the fear of delivery and sense of coherence in women.

\section{REFERENCES}

1.Saisto T, Halmesmäki E. Fear of childbirth: a neglected dilemma Acta Obstet Gynecol Scand. 2003; 82: 201-208. https://doi.org/10.1034/ j.1600-0412.2003.00114.x

2. Faisal-Cury A, Rossi Menezes P. Prevalence of anxiety and depression during pregnancy in a private setting sample. Arch Womens Ment Health. 2007; 10(1): 25-32. doi:10.1007/s00737-006-0164-6

3. Areskog B, Uddenberg N, Kjessler B. Fear of childbirth in late pregnancy. Gynecol Obstet Invest. 1981; 12(5): 262-266. doi:10.1159/000299611

4. Sarkar P, Bergman K, O'Connor TG, Glover V. Maternal antenatal anxiety and amniotic fluid cortisol and testosterone: possible implications for foetal programming. J Neuroendocrinol. 2008; 20(4): 489-496. https://doi.org/10.1111/j.1365-2826.2008.01659.x

5. Sandman C, Wadhwa P, Glynn L, Chicz-Demet A, Porto M, Garite T. Corticotrophin囚releasing Hormone and Fetal Responses in Human Pregnancy. Ann N Y Acad Sci. 1999; 897: 66-75. https:/doi. org/10.1111/j.1749-6632.1999.tb07879.x

6. Fink NS, Urech C, Berger CT, et al. Maternal laboratory stress influences fetal neurobehavior: cortisol does not provide all answers. J Matern Fetal Neonatal Med. 2010; 23(6): 488-500. doi:10.3109/14767050903300985

7. DiPietro JA, Novak MF, Costigan KA, Atella LD, Reusing SP. Maternal psychological distress during pregnancy in relation to child development at age two. Child Dev. 2006; 77(3): 573-587. doi:10.1111/j.14678624.2006.00891.x

8. Wachholtz AB, Pargament KI. Migraines and meditation: does spirituality matter? J Behav Med. 2008; 31(4): 351-366. doi:10.1007/ s10865-008-9159-2

9. Sekizuka N, Nakamura H, Shimada K, Tabuchi N, Kameda Y, Sakai A. Relationship between sense of coherence in final stage of pregnancy and postpartum stress reactions. Environ Health Prev Med. 2006; 11(4): 199-205. doi:10.1007/BF02905279

10. Alireza AY, Nasim S. Analysis of the relationship between sense of coherence and emotional intelligence in university students. Psychol Stud. 2011; 7(3): 51-73

11. Antonovsky A. The structure and properties of the sense of coherence scale. Soc Sci Med. 1993; 36(6): 725-733. doi:10.1016/02779536(93)90033-z

12. Putyński L, Paciorek M. Kwestionariusz lęku porodowego (KLPII) Wersja zrewidowana- Konstrukcja i właściwości psychometryczne. Acta universitalis Lodziensis, Folia Psychologica. 2008; 12: 129-133.

13. Melender HL. Experiences of fears associated with pregnancy and childbirth: a study of 329 pregnant women. Birth (Berkeley, Calif.) 2002; 29(2): 101-111. https://doi.org/10.1046/j.1523-536x.2002.00170.x

14. Mohamamdirizi S, Mohamadirizi M, Mohamadirizi S. The comparison of fear of childbirth and sense of coherence among low-risk and highrisk pregnancy women. J Educ Health Promot. 2018; 7: 143. Published 2018 Nov 27. doi:10.4103/jehp.jehp_179_17

15. Takegata M, Haruna M, Matsuzaki M, Shiraishi M, Okano T, Severinsson E. Antenatal fear of childbirth and sense of coherence among healthy pregnant women in Japan: a cross-sectional study. Arch Womens Ment Health. 2014; 17(5): 403-409. doi:10.1007/s00737-014-0415-x

16. Antonovsky Unraveling the mystery of health: how people manage stress and stay well. Jossey-Bass Publishers, San Francisco; 1987.

17. Carlsson IM, Ziegert K, Nissen E. The relationship between childbirth self-efficacy and aspects of well-being, birth interventions and birth outcomes. Midwifery. 2015; 31(10): 1000-1007. doi:10.1016/j. midw.2015.05.005

18. Ryding EL, Read S, Rouhe H, et al. Partners of nulliparous women with severe fear of childbirth: A longitudinal study of psychological wellbeing. Birth. 2018; 45(1): 88-93. doi:10.1111/birt.12309

19. Sheen K, Slade P. Examining the content and moderators of women's fears for giving birth: A meta-synthesis. J Clin Nurs. 2018; 27(13-14): 2523-2535. doi:10.1111/jocn.14219

20. Alder J, Breitinger G, Granado C, et al. Antenatal psychobiological predictors of psychological response to childbirth. J Am Psychiatr Nurses Assoc. 2011; 17(6): 417-425. doi:10.1177/1078390311426454

21. Goutaudier N, Bertoli C, Séjourné N, Chabrol H. Childbirth as a forthcoming traumatic event: pretraumatic stress disorder during pregnancy and its psychological correlates. J Reprod Infant Psychol. 2019; 37(1): 44-55. doi:10.1080/02646838.2018.1504284

22. Striebich S, Mattern E, Ayerle GM. Support for pregnant women identified with fear of childbirth (FOC)/tokophobia - A systematic review of approaches and interventions. Midwifery. 2018; 61: 97-115. doi:10.1016/j.midw.2018.02.013

23. Abdollahi S, Faramarzi M, Delavar MA, Bakouei F, Chehrazi M, Gholinia H. Effect of Psychotherapy on Reduction of Fear of Childbirth and Pregnancy Stress: A Randomized Controlled Trial. Front Psychol. 2020; 11: 787. Published 2020 May 26. doi:10.3389/fpsyg.2020.00787

24. Söderquist J, Wijma B, Thorbert G, Wijma K. Risk factors in pregnancy for post-traumatic stress and depression after childbirth. BJOG, 2009; 116(5): 672-680. https://doi.org/10.1111/j.1471-0528.2008.02083.x

25. Moghaddam Hosseini V, Nazarzadeh M, Jahanfar S. Interventions for reducing fear of childbirth: A systematic review and meta-analysis of clinical trials. Women Birth. 2018; 31(4): 254-262. doi:10.1016/j. wombi.2017.10.007 